\title{
GAUGING THE USAGE OF THE INTERNAL MARKETING BY TEACHERS FOR EFFECTIVE TEACHING AND COMMUNICATION
}

\author{
Simmy Kurian ${ }^{1}$, Berislav Andrlic ${ }^{2}$ and Hareesh N Ramanathan ${ }^{3}$ \\ ${ }^{I}$ Toc H Institute of Science \& Technology,Arakkunnam, P.O.,Ernakulam District, Kerala, India \\ ${ }^{2}$ Vice-Dean for Development, Polytechnic in Pozega, Croatia \\ ${ }^{3}$ Professor \& Head, Business \& Management Studies, Jain University, Kochi Kerala, India
}

\begin{abstract}
With a whole new array of technological developments in and around the world ----" The Technology means" are the strongest way to communicate and create long lasting impact on peoples' minds. As far as teachers are concerned technology enabled teaching environment can positively reinforce their teaching methodology. The internet which is an internetwork of networks and integrates Information and communication technologies, can be used as an effective means for communicating with the students This study assesses the internet usage by teachers of high schools and higher secondary schools along thirteen different categories of uses of the internet for various teaching learning processes. The data was collected from three zones constituted by 14 districts in the Indian state named Kerala. The data was analysed using Friedman's two-way analysis of variance test to gauge the teachers ranking of thirteen popular uses of the Internet. The rankings revealed that the most popular use of the internet was accessing course content, followed by teaching of subjects, performance evaluations and communicating with subject experts. The least ranked categories of use were gaining computer skill, presentation, searching information and communicating with stakeholders like students, parents and teachers. These rankings are indicative of teacher preferences relating to the usage of Internet resources for various teaching learning activities. The results raise several concerns regarding the areas where there is potential for better use of the internet in the future.
\end{abstract}

\section{KEYWORDS}

Internet, Technology Enabled Teaching, Communication with Subject Experts, Access to Course Content, Performance Evaluation

\section{INTRODUCTION}

Developments in communication technology are having a deep and distinct impact on the traditional educational system both in elementary schools and higher education institutions. Teachers play a crucial role in helping individuals gain adequate expertise in using the learning networks audaciously and accessing information available on the Internet. Study tried to assess the popular uses of the internet by teachers for various teaching learning processes. The assessment categories included access to course content, presentation, lesson plan preparation, performance evaluation, communication, new content creation, bookmarking and collaboration. The paper aims at ascertaining the teachers perception on the usefulness of the internet in streamlining various teaching learning processes especially along dimensions like the use of internet as an reservoir of content for enhancing the classroom teaching environment, the use of Internet as a means for communicating with different stakeholders who are part of the teaching learning process, the use of Internet for creation of new educational content, use of internet for preparation of lesson plan and the use of Internet for monitoring student progress. 


\section{LITERATURE REVIEW}

With the internet reaching beyond the boundaries of both domestic and public environments, it upholds great challenges as well as opportunities for improving the education system. The opportunities come by way of free and open communication, identity, wide spread literacy and participation while the challenges come by way of fear of exclusion, inappropriate content and digital divide (Livingstone, 2003). (Uluyol \& Sahin, 2014) the authors suggested that teachers play a significant role in integrating information and communication technology (ict) in schools, and motivated teachers reflect higher levels of ICT use in their classroom. The discussion that accrued from the study helped to understand the current state of teachers' technology use and their motivations for using technology. The development of the internet has brought about a revolutionary change in the perspective of teachers towards the use of information and communication technology in teaching, as the tools that were offered by technology, today are becoming more and more reliable. (A.K. Jager \& A.H. Lokman, 1999) emphasized that although teachers consult each other more frequently, the teacher eventually decide on the educational practice in their class room. Education and teacher are tied to a specific content of education, timetables, amount of face-to-face instruction, instruction time, class rooms etc. even the teacher's status is laid down (Wolf, 1998). Contemporary Information and communication technology aides are able to provide strong support for all these requirements and there are now many outstanding examples of world class settings for competency and performance-based curricula that make sound use of the affordances of these technologies (Oliver, 2000). The integration of information and communication technologies can help revitalize teachers and students. The rapid development of the internet, although has greatly raised teacher interest in technology tools provided by internet for teaching learning purposes, little is known about their actual use of it. (SHIN, 2007). The role of teachers in motivating and guiding students' use of technology is of primary concern, as a study reported that students acceptance of internet based learning medium was greatly influenced by both the extrinsic factor called perceived usefulness as well as the intrinsic factor perceived enjoyment while the ease of use of technology, according to the author did not have a significant influence on the use of it (Matthew K.O. Lee, 2005). Teachers could therefore build up their classroom and curriculum activities integrating various internet based tools so as to enhance the students' perceived usefulness of technology as well their perceived enjoyment of it.

\section{METHODOLOGY}

Exploratory research was carried out for the purpose of the study. In order to study internet usage pattern of teachers, initially various stakeholders were interviewed and focus group discussions were held to ascertain the major categories of use that internet could serve teachers. Gradually the search revealed thirteen various categories of use that seemed were mostly preferred by teachers. Descriptive design was adopted in the next stage of the study which falls into a conclusive design. A questionnaire was formed based on the responses collected in the exploratory phase and the same was used to collect the data for the study. The researcher collected data on the basis of these thirteen categories of internet use relating to various teaching learning processes. The respondents were asked to rate each category of internet use on a scale of ranging from a minimum score of one to a maximum score of 10 . These ratings were beneficial to the researcher in tabulating the relative ranking for each of these thirteen categories of internet use. All high schools and higher secondary government and aided schools in the Indian state of Kerala were considered for this study. A total of 342 respondents were part of the survey in all from the three zones of the state.

\subsection{Respondent Profile}

The survey comprised of 342 teachers from across the state apportioned across three zones. Out of the total sample, 147 respondents were undergraduate teachers out of which 27 were males and 120 were females while 195 of the teachers were post graduates out of which 50 were males and 145 were females as in the table 1. 
Table 1. Gender \& Qualification details of respondents: source(primary data)

\begin{tabular}{cccc}
\hline & \multicolumn{3}{c}{ Gender and Qualification } \\
& Qualification & Total \\
Male & UG & PG & 77 \\
Female & 27 & 50 & 265 \\
& 120 & 145 & 342 \\
\hline
\end{tabular}

\subsection{Teaching Experience}

The researcher included teachers who had average teaching experience of 15 years so that they would be able to judge better the transition of the teaching learning environment of the schools to the technology enabled era.

Table 2. Teaching Experience of Teachers : source(primary data)

\begin{tabular}{llcc}
\hline & \multicolumn{2}{c}{ Years_of_Experience } \\
\hline \multirow{3}{*}{ Valid } & Frequency & Percent \\
& less than & 149 & 44.0 \\
12.5 yrs & & \\
$13-24.5 y r s$ & 165 & 48.0 \\
& & 28 & 8.0 \\
& $>25 y r s$ & 342 & 100.0 \\
\hline
\end{tabular}

The table 2 depicts that $48 \%$ of the respondents possessed a teaching experience of 13 to 24 years.

\subsection{ICT Use by Subject}

Teachers: It was found that technology usage was mostly predominant among science teachers, this was followed by the use of technology means by teachers teaching ICT as a subject itself.

\subsection{Time spend by the Teachers in the Use of ICT Tools}

It was observed that only $34 \%$ of the respondents spent around 5-7 hrsa week in using various technology tools while majority reported using the same for about less than $5 \mathrm{hrs}$ as seen in the table 3 .

Table 3. Time spend in using ICT tools by Teachers: source(primary data)

\begin{tabular}{|c|c|c|c|}
\hline \multicolumn{4}{|c|}{ Use of TechnologyTools_in_School } \\
\hline & & Frequency & Percent \\
\hline \multirow{3}{*}{ Valid } & less than $5 \mathrm{hrs}$ & 152 & 44.4 \\
\hline & $5-7 \mathrm{hrs}$ & 115 & 34.0 \\
\hline & more than $7 \mathrm{hrs}$ & 75 & 21.0 \\
\hline
\end{tabular}




\subsection{Internet usage by Teachers}

Based on previous studies that assessed ICT usage of teachers, thirteen broad categories of Internet usage were defined for the study. Teachers were asked to rank the above mentioned thirteen categories of uses of internet for educational purposes and these responses were used to analyse the most preferred and the least preferred usage category. Friedman's rank order test was carried out to analyse the luxury buying preference of consumers on the selected product categories. Here K related samples mean the test was used to compare the eleven variables measured on the same respondents.

\subsubsection{Pair-Wise Comparisons (Nonparametric Tests)}

Related-samples Friedman's two-way analysis of variance test was conducted in order to identify if the internet usage categories vary according to the respondents. K-sample non-parametric tests produce a distance chart and comparisons table when pairwise multiple comparisons are required.

Pairwise comparisons were carried out using the following hypothesis.

HO: The distributions of computer skills, searching information, presentation, lesson preparation, communication with students, communication with teachers, communication with parents, performance evaluation, preparation of reports bookmarking course contents, contact experts and teaching subjects are the same.

H1: The distributions of computer skills, searching information, presentation, lesson preparation, communication with students, communication with teachers, communication with parents, performance evaluation, preparation of reports bookmarking course contents, contact experts and teaching subjects are different

Table 4. Mean Ranks of the Internet Usage Categories (Source: Survey Data)

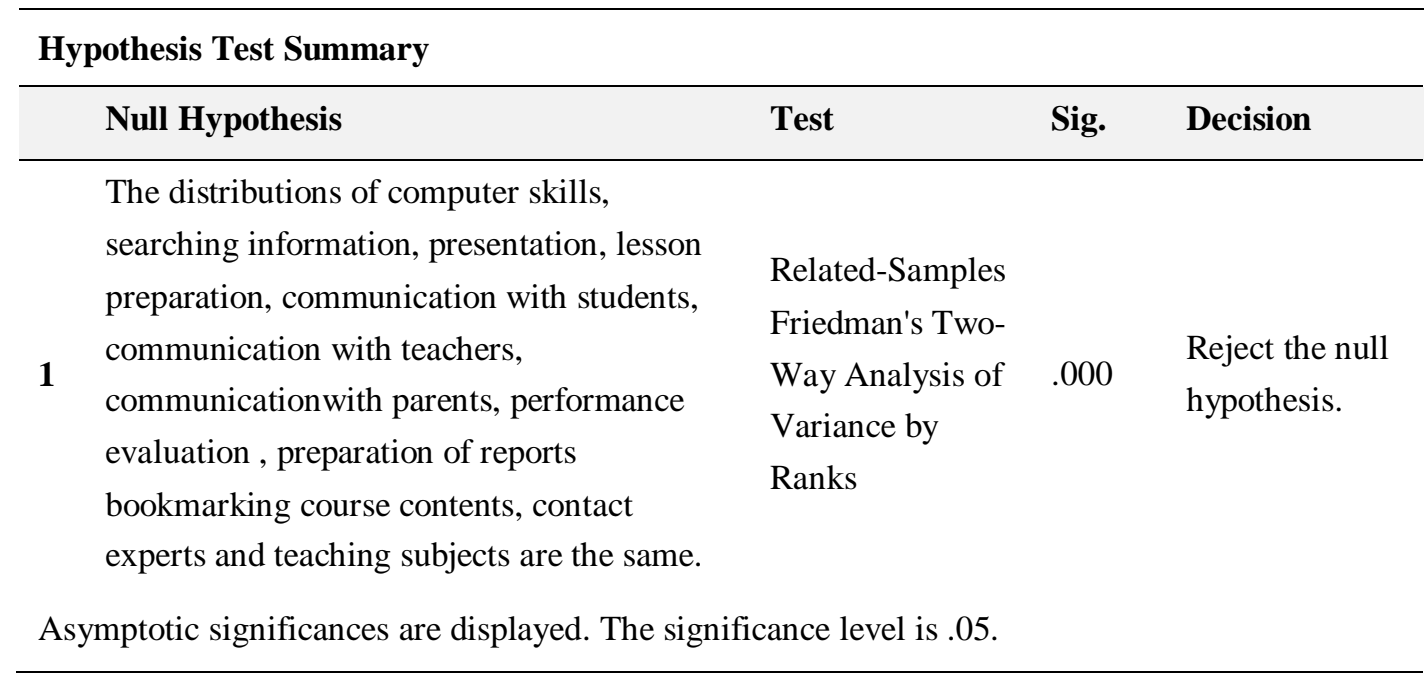

The hypothesis test result proves that there is the significant difference between at least two internet usaget categories (as $\mathrm{p}<0.001)$; therefore the null hypothesis was rejected.

Both Figure 1 and Table 5, depicts the mean ranking pattern. The Friedman test ranks each person's score from lowest to highest (as the first rank was assigned to the most popular internet use category and eleventh rank were assigned to the least popular internet use category) and bases the test on the sum of ranks for each column. Hence the category with the least mean ranking score will be the most popular use of internet among the teachers. Here the test statistic summarizes how differently the internet usage categories were rated in a single number. Friedman test signifies that the categories were rated differently with test statistic 411.191 $\& \mathrm{p}=0.000$ (Figure 1). 


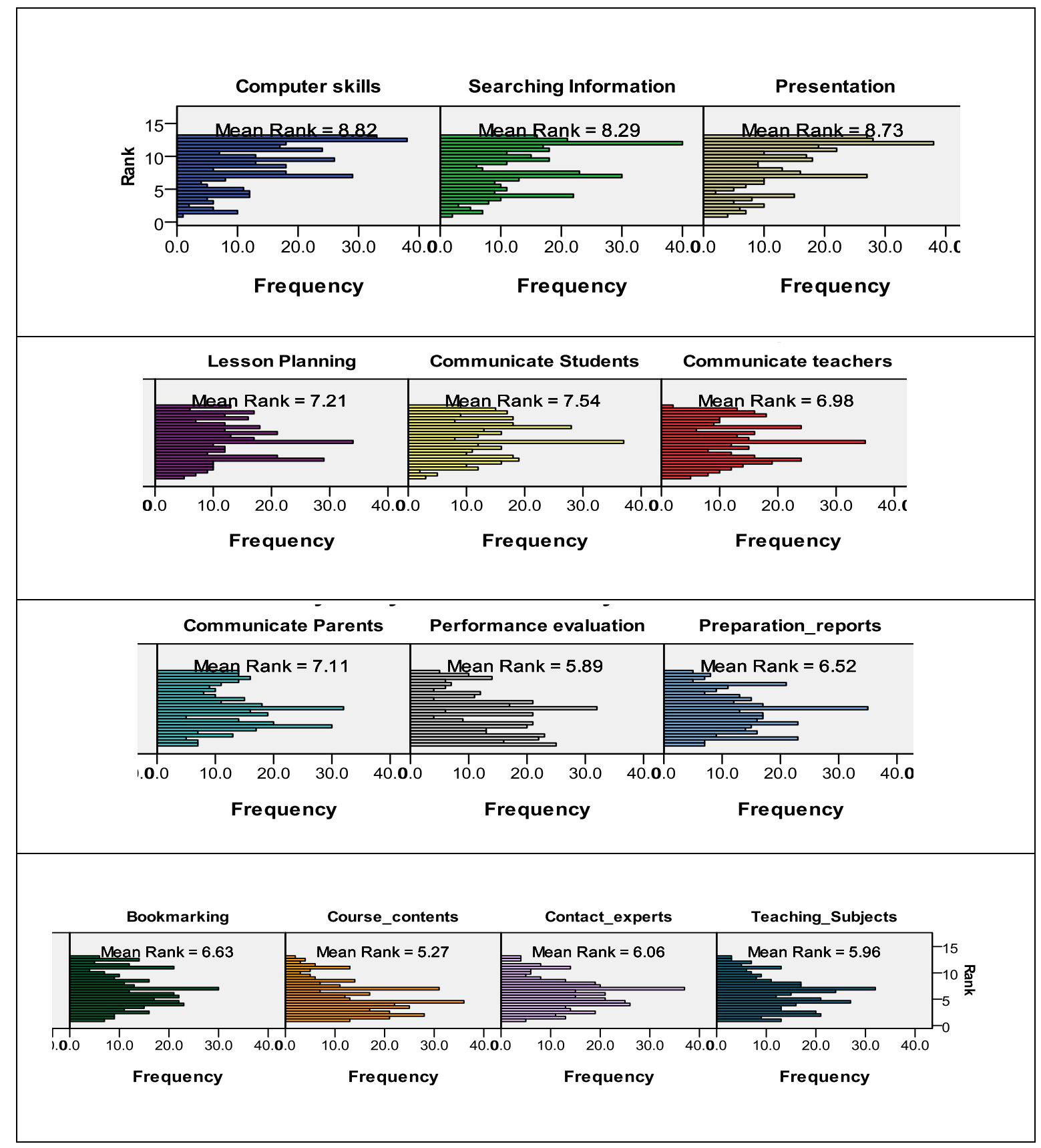

\begin{tabular}{|lr|}
\hline Total N & 342 \\
\hline Test Statistic & 411.191 \\
\hline Degrees of Freedom & 12 \\
\hline Asymptotic Sig. (2-sided test) & .000 \\
\hline
\end{tabular}

Figure 1. Mean Rank of Internet Usage Category on the Basis of their Popularity 
Table 5. Mean Ranks of the Popular Internet Usage Categories

\begin{tabular}{lcc}
\hline Internet Use Category & Mean Rank & Rank \\
\hline Course contents & 5.27 & 1 \\
\hline Teaching subjects & 5.96 & 2 \\
\hline Performance evaluation & 5.89 & 4 \\
\hline Contact experts & 6.06 & 5 \\
\hline Preparation of reports & 6.52 & 6 \\
\hline Bookmarking & 6.63 & 7 \\
\hline Communicate with teachers & 6.98 & 8 \\
\hline Communicate with parents & 7.11 & 9 \\
\hline Lesson Plan Preparation & 7.21 & 10 \\
\hline Communicate with students & 7.54 & 11 \\
\hline Searching Information & 8.29 & 12 \\
\hline Presentation & 8.73 & 13 \\
\hline Computer skills & 8.82 & 3 \\
\hline
\end{tabular}

Source: Survey Data

Pairwise Comparisons

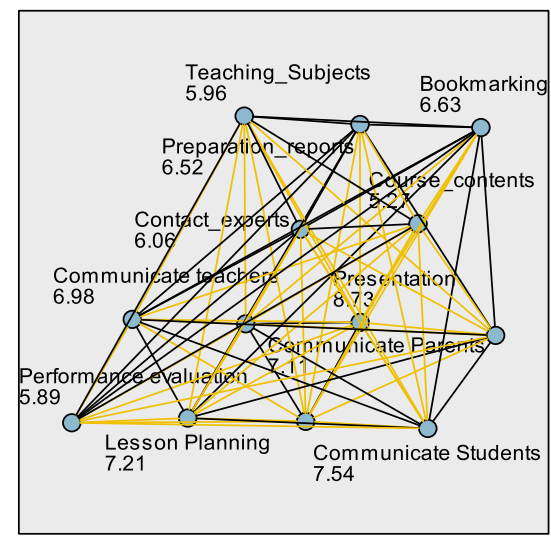

Figure 2. Pair-wise Comparison of the Internet Usage Categories

The pairwise comparison of various Internet usage categories is pictorially depicted in Figure 2. Each node in the figure shows the mean rank for each of the usage categories. The distance network chart is a representation of the comparison table in which the distances between nodes in the network corresponds to 
differences between samples. Yellow line corresponds to statistically significant differences between the pairs; black lines correspond to non-significant differences. In Figure 2, it could be seen that the most preferred usage category accessing course contents with the mean score (5.27) significantly varies from usage categories like presentation, bookmarking, communication with teachers, communication with parents and communication with students. Interestingly there is significant difference between the usage categories 'accessing course content' and 'searching information', 'teaching subjects' and 'presentation'.

\section{IMPLICATIONS AND CONCLUSION}

This study was an attempt to assess the various beneficial categories of uses that the internet could serve for teachers in their quest for making teaching learning processes more and more effective. The research survey was initiated with the premise of thirteen popular uses of the internet that teachers claimed to benefit from. The rankings derived from the respondents' feedback revealed that the most popular uses of the internet were to access course content, teaching of subjects, performance evaluations, report preparation and contacting experts which were the most highly ranked categories of use. While the least ranks were assigned to use of internet for communication with various stakeholders like students, parents and teachers, upgrade computer skills and presentation. The implications of this study are important for both researchers as well as practitioners. The current study, hints at the existing perception of its use among the teachers who are yet to explore the internet to its full. Therefore it is recommended that the educational institutions provide greater backbone support in terms of infrastructure, time, flexibility and adequate training to the teachers who would then leverage the benefits of this vast information and communication network.

\section{REFERENCES}

A.K. Jager , \& A.H. Lokman. ( 1999). Impacts of ICT in education. The role of the teacher and teacher training. Paper Presented at the European Conference on Educational Research, (pp. 22 - 25). Lahti, Finland.

Assocham, I. (2016, January 7). www.assocham.org. Retrieved Febrauary 14, 2017, from www.assocham.org: http://www.assocham.org/newsdetail.php?id=5440

Lee, K. (2000). English teachers' barriers to the use of Computer-assisted Language Learning. The Internet TESL Journal, Vol. VI, No. 12, December 2000, http://iteslj.org/.

Livingstone, S. (2003). Children's Use of the Internet: Reflections on the Emerging Research Agenda. Sage Journals, Volume: 5 issue: 2 , page(s): 147-166.

Matthew K.O.Lee, C. M. ( 2005). Acceptance of Internet-based learning medium: the role of extrinsic and intrinsic motivation. Information \& Management, Elseveir, Volume 42, Issue 8, December, 1095-1104.

Oliver, R. (2000). Creating Meaningful Contexts for Learning in Web-based Settings. Proceedings of Open Learning 2000.: Learning Network, (pp. 53-62). Brisbane, Queensland.

Shin, H.-J. a.-B. (2007, Oct 11). EFL teachers' perceptions and perspectives on internet-assisted language teaching. Retrieved sept 23, 2019, from University of Southern Queensland eprints: http://eprints.usq.edu.au/id/eprint/1924

Silverstein, M. J., \& Sayre, K. (2009, September). The Female Economy. Harward Business Review.

Uluyol, C., \& Sahin, S. ( 2014). Elementary school teachers' ICT use in the classroom and their motivators for using ICT. British Journal of Educational Technology, 47(1).

Wolf, H. d. (1998). Toekomstgericht onderwijs en het gebruik van informatie- en communicatietechnologie. Hoe te komen te verantwoorde keuzen. Commissie Prommitt; [S.l.] : Open University Netherlands. Alphen aan den Rijn: Samsom. 